\title{
Role of Performance Contracting in Enhancing Effectiveness of Performance in the Civil Service in Kenya, State Department of Infrastructure
}

\author{
Prof. R.W. Gakure, Stephen Macharia Muriu, Dr. George Orwa \\ Jomo Kenyatta University of Science and Technology (JKUAT), Kenya
}

\begin{abstract}
The management of the Public Service in Kenya has been a challenge and has been undergoing changes and evolving over time towards improved service delivery to the citizens and none has born better results than performance contracting. Key trend in the New Public Management (NPM) approach in crisis states is the increasing resort to performance contracting as an instrument to reform state-owned enterprises. Introduction of performance contracting emanated from the realization that public service was not clear about its goals as it had several functions with multiple objectives to fulfill where some were not related to their core mandate. It's also from realization that what gets measured gets done, a philosophy that has been practiced widely in the private sector.

The study established that performance contracting enhanced effectiveness of performance in service delivery in the civil service in Kenya and particularly in the State Department of Infrastructure. Literature was reviewed to broaden the view of management of public service systems and performance contracting in particular. The Department under study was divided into five heterogeneous divisions (stratum) and a sample of 108 out of 1072 was got through proportionate stratified sampling method. Statistical Package for Social Scientists (SPSS) was used in the descriptive and inferential data analyses to establish meanings and relationships. Correlations revealed a strong relationship of (0.596) between performance contracting and effectiveness of performance. $R$-Square indicated that performance contracting explained $31.6 \%$ of effectiveness of performance. Analysis of variance (ANOVA) established that performance contracting is significant on performance while regression model established that a unit increase in performance contracting resulted to an increase in effectiveness of performance by 1.22 units which is significant at a p-value of 0.000 . These results provided and revealed an important aspect bearing the effort and cost the government is putting in the performance contracting tool. It is concluded from the findings that performance contracting leads to effectiveness of performance and therefore recommended that more resources need to be used to fast track the tool in the entire public service.
\end{abstract}

Key Words: Performance Contracting, Effectiveness of Performance, ANOVA and Regression Model

\section{Background}

Poor public performance in the Kenya public sector consistently hindered the realization of sustainable economic growth and development since the country attained her independence in 1963 (Mbithi, 1996). Among the noted factors that contribute to poor performance included; excessive regulations and control, frequent political interference, poor management, outright mismanagement of resources and lack of a guiding vision (Government of Kenya, 2005). Lack of clear focus as to what is expected from employees and poor or no methods of measuring performance has been the greatest challenge (Muthaura, 2007). The Government elected in 2003 decided to manage public service through performance contracting system to address the situation.

According to Lardi (1999), performance contract is defined as a written or negotiated agreement between government or its representative agency and the management of public enterprises and other autonomous units directly delivering services to public, or between government and private managers of state assets, wherein quantifiable targets are explicitly specified for a given period and performance is measured against targets at the end of the period (World Bank, 1995:171).

As part of the performance-orientation in government, the common purposes of performance contracting are to clarify the objectives of service organizations and their relationship with government, and to facilitate performance evaluation based on results instead of conformity with bureaucratic rules and regulations (Mallon, 1994; Islam, 1993).

\section{Global Perspective}

Globally, a paradigm shift in performance management in the public enterprises as argued by Shaver (2006) and United Nations (2007) is as a result of different practices of performance management by the public sector, explosion of knowledge and human rights activities. Ndung'u (2009) observed that Governments are 
faced with the challenge of improving service delivery while using fewer resources to deliver effective and efficient services demanded by the citizens.

Gakere (2013) noted that in Asia, the performance contract concept has been used in Bangladesh, China, India, Korea, Pakistan and Sri Lanka, Latin America, Argentina, Brazil, Bolivia, Chile, Colombia, Mexico, Uruguay and Venezuela. Others include Malaysia, United Kingdom, U.S.A, and Canada.

In Belgium, performance contracting in the public sector dates back to the breaking of the traditional monolithic government in the 1830s and stipulated the compulsory public utility service being provided by the agency and the government's conditions (Bouckaert, Verhoest \& Cortek 1999). Although the paradigm of performance contracting in Belgium dates back in the 1800s, its science originated from France in the 1960s according to research done by Bouckaert et al (1999) and subsequently embraced by Pakistan and Korea and India.

In United Kingdom (UK), performance contracting in public sector was introduced in 1998 as Public Service Agreement (PSA) system and outlined a set of performance targets which all government agencies were to report on (Metawie and Gilman, 2005). Grapinet (1999) noted that in Finland, major public service reforms were introduced during 1987-1997 according to study on Public Sector Performance Contracting and the aim was to make public agencies more responsible and accountable. In Denmark according to May (2005), performance contract played a major role in improving efficiency and increasing policy control and in United State of America (USA) according to Government Performance and Results Act of 1993, performance contract aimed at making federal departments more productive and therefore boosts citizens' confidence in their government.

\section{Africa Perspective}

In African countries, experience of poor performance public agencies called for new comprehensive public sector reforms strategy to address these problems. Countries such as Ghana, Nigeria, Gambia and Kenya in 2005 started managing public service through performance contracting (Kobia \& Mohammed 2006). Ndung'u (2009) noted that the East African Community (EAC) performance Contract 2008/2009 stipulated expectations of member states (Kenya, Uganda, and Tanzania) commitment for common achievement including implementation of Strategic Plan (2007-2012) which was to ensure that appropriate work plans are developed on the basis comprehensive performance targets.

\section{Kenyan Perspective of Performance Contracting}

In Kenya, Performance contracting concept can be traced back in 1990 through Cabinet Memorandam No. CAB (90) 35 when performance contracting paradigm was conceived and designed with an aim of having a real impact in changing the way things were being done, creating a new behavior patterns and adoption of positive attitude work ethics in the entire public service delivery (Kobia and Mohammed 2006). The system was expected to return faith on government services to the citizens and other international stakeholders (Muthaura, 2007). The paradigm was later outlined in the Economic Recovery Strategy for Wealth and Employment Creation (ERS) 2003-2007.

\section{Statement of the Problem}

Effectiveness of performance in the Kenya civil service has been noted to be a big challenge and below the expectations and led to strained national budget without equivalent results (Prajapati, 2009; Muthaura, 2007; GOK, 2005). In response, the government has been undertaking a number of reforms to address the situation in the last two decades. Such reforms include; Freezing of Employment and Structural Adjustment Program (SAP) in the early 1990s, Voluntary Early Retirement (VER), Retrenchment Program in the mid 1990s early 2000s and introduction of Integrated Payroll and Personnel Database (IPPD), Salary Review and Strategies for uprooting corruption from the public service (DPM, 2010) among others.

In 2005, the government made a major stride by introducing performance contracting paradigm in the management of public service and a positive paradigm shift in performance has been recorded (Government of Kenya, 2010; Oduor, 2010; Muthaura, 2009; Prajapati, 2009; Obong'o, 2008; Kobia \& Mohammed 2006).

Table 1 illustrates the trend of Economic Growth for the period 2003-2011 with implementation of performance contracting of which 3\% of the National Gross Domestic Product (NGDP) is contributed by the infrastructure sector. The downwards trend for year 2008 were revised downwards due to the post-election violence and devastating famine and for global economic recession, inflation rates and draught during year 2011. 
Table 1 Economic Growth for the Period 2003-2011

Source: GoK (2011)

\begin{tabular}{|c|c|c|c|c|c|c|c|c|c|}
\hline Year & $\mathbf{2 0 0 3}$ & $\mathbf{2 0 0 4}$ & $\mathbf{2 0 0 5}$ & $\mathbf{2 0 0 6}$ & $\mathbf{2 0 0 7}$ & $\mathbf{2 0 0 8}$ & $\mathbf{2 0 0 9}$ & $\mathbf{2 0 1 0}$ & $\mathbf{2 0 1 1}$ \\
\hline \% GDP rate & 2.0 & 4.3 & 5.8 & 6.1 & 7.0 & 1.7 & 2.8 & 5.6 & 4.5 \\
\hline
\end{tabular}

Implementation of the performance contracting in the public service aimed at revolutionizing service delivery in the public service (Prajapati 2009; Obong'o 2008; Muthaura 2007, Kobia \& Mohammed 2006).

In their studies, Muthaura 2007, Kobia \& Mohammed 2006 and GoK 2010 reckoned that a deeper study was required to unearth and reveal understanding on the role of performance contracting on variables such as productivity, employees' motivation, organizational culture and organization effectiveness. All these factors combined form the effectiveness of performance in the civil service.

In view of the foregoing, this study therefore investigated the effects of performance contracting on effectiveness of performance in the Civil Service in the state Department of Infrastructure.

\section{Literature Review}

Hale (2004) noted that from a performance improvement perspective, employees deserve clear direction form management. Employees should have a clear understanding of what the organization is trying to accomplish and what role they play in making it happen (Pfeffer, 1998). The first principle of performance is to focus on results and avoid the risk of losing sight of the outcomes that are required to meet the organization's goals.

Employees' focus is about making sure goals, objectives, activities, deliverables, and measures are aligned and congruent. Once people know the goals, they should know what is expected of them and the direction the organization is heading, they will require tools that help them perform the job. Finally, they should get a crue or signals to help them stay on course through feedback.

Performance contracting is a summation of various bodies of knowledge applied together with an intention of improving organization performance. Various theories cutting across different bodies of knowledge have therefore been advanced to support and explain performance contracting paradigm. Muthaura (2007) asserts that performance contracting is both a philosophy and a tool for coordinating employees towards achievement of results. Performance contracting was premised to lead to increase in effectiveness of performance.

\section{Conceptual Framework}

\begin{tabular}{|c|c|}
\hline $\begin{array}{l}\text { Performance Contracting } \\
\begin{array}{l}\text { - Role of PC } \\
\text { - Global Trends \& ICT } \\
\text { - Employees Training } \\
\text { - Work Measurement } \\
\text { - Ranking }\end{array}\end{array}$ & $\begin{array}{l}\text { Effectiveness of Performance } \\
\text { - Productivity } \\
\text { - Employees' Motivation } \\
\text { - Organizational } \\
\text { - } \text { Effectiveness } \\
\text { Organizational Culture }\end{array}$ \\
\hline
\end{tabular}

\section{Regressed \\ Figure1. Performance Contracting on Effectiveness of Performance in the Civil Service in Kenya}

\section{Theoretical Literature}

Relevant theories that address organization performance such as Scientific Management by F.W. Taylor (1856-1915), Principles of Management: Henry Fayol (1841-1925), Bureaucracy Theory by Max Weber heavily informed the science behind performance contracting paradigm. Motivation theories such as RationalEconomic Model, Social Model, Self-Actualizing Model, Complex Model, Abraham Maslow Model, McGregory Theory X and Theory Y, Herzberg's Two-Factor Theory, Achievement Motivation by McClelland and Vroom's Expectancy Theory among others enabled the paradigm to be sensitive on the human aspect in the civil service.

\section{Empirical Literature}

Past studies were also reviewed to analyze and evaluate work already done in the area. In the study "Performance Contracts in Kenya: Instruments for Operationalizing Good Governance" based on the results for year 2005-2006, Prajapati (2010) reckoned that Performance Contract (PC) is an agreement between the government as the client and a public agency (managers) which establishes general goals for the agency, sets 
targets for measuring performance and provides incentives for achieving these targets and reprimand for nonperformance. The study revealed that any effort to measure performance results to positive results because employees' efforts are focused to organization's objectives thus improving performance. However the study failed to relate performance contracting to performance effectiveness.

Government of Kenya (2010) through a Panel of Experts set up to review Performance Contracting since implementation in 2004 studied the PCs and shed light on areas such as: the framework and design of the performance contracting system applied since 2004; the performance contracting process; the performance contracting evaluation system and process; the critical learning points from the performance evaluation results reported over the past three financial years, and citizen participation, expectations and perceptions. The report was too broad and failed to address specific areas such as quantified effects of performance contracting on performance.

"Public Sector Reforms and Performance Contracting" study by Ochieng (2010) observed that in the 1990s, Kenya's Public Service was among the countries which had suffered "damaged image" both locally and internationally. The study revealed that performance contracting has instilled discipline to the public institutions by ensuring adherence to work-plans, strategic plans, sector plans and Vision 2030 has its foundation laid on performance contracting. The study noted that the paradigm enabled recognition of performers from nonperformers thus leading to a competitive public service. Obong'o (2009) in the "Review on Performance Contracting in Kenya" based on results for the year 2005-2006 asserted that introduction of performance contracts by the government in 2004 has improved performance, service delivery and governance. The study was descriptive based on the secondary data.

Kobia \& Mohammed (2006) in a study "Kenya Experience with Performance Contracting" reckon that performance contracting has revolutionized service delivery in the public service. The study assumed a descriptive and qualitative design and results were based on 280 senior public servants who were attending a workshop at Kenya Institute of Administration and were drawn from various ministries across the country. This implies that the study was spread so thin to enable sound conclusion.

The study noted that performance contracting ensures that employees are guided and facilitated by work-plans and are made responsible for their results. The system enables measuring the extent to which the set targets has been achieved and enables coordination of the individual, department, institution and ministries to derive their plans from the country's envisioned development blue print Vision 2030.

Muthaura (2007) argues that performance contracting forms a very strong base for employees' employment terms of service since they have to justify their stay in the payroll through performance and reckon that "every employee has to justify why they should be retained in the payroll through performance". The study noted that performance contracting has demystified government and governance processes thus ensuring inclusion of grass roots level communities.

\section{Research Gap}

The above literature notwithstanding, it's clear that no detailed study has been carried out to specifically explain the effects of performance contracting on performance effectiveness, concentrating on the organizational productivity, organizational culture, organizational effectiveness and employees' motivation which this study premised to be the effectiveness of performance. This research study therefore investigated and quantified effects of performance contracting on performance effectiveness in the civil service in Kenya in the State Department of Infrastructure.

\section{Research Design}

\section{Research Methodology}

According to Sekaran \& Roger (2011), research design is a master plan that specifies the methods and procedures for collecting and analyzing the needed information. Cooper and Schindler (2006) argue that research design constitutes the blue print for the collection, measurement and analysis of the data to achieve fore stated objectives. It's a structure for investigating so conceived as to obtain answers to research questions and for testing hypothesis (Kothari, 2004). Quantitative and qualitative designs were employed. According to Zikmund et al (2010), exploratory design is undertaken when the characteristic or the phenomenon to be tapped in a situation are known to exist but little literature and empirical exist to offer support. Sekaran \& Roger (2011) reckon that exploratory research is conducted to clarify ambiguous situation or discover potential opportunities. The study was also exploratory because scanty information exists on the role of performance contracting in the organizations in relation to performance effectiveness (Orodho, 2003). Descriptive and inferential designs were also applied.

Population

Cooper and Schindler (2006); Kothari (2004); Mugenda \& Mugenda 2003; Hyndman 2008) define population as the total collection of elements that is the main focus of a scientific query. Every employee in the 
Ministry is under performance contract whether direct or indirect and hence had the characteristic of interest for this study. Employees are divided into five major departments based on area of specialization and include: Kenya Institute of Highways and Building Technology (KIHBT) 161, Materials 145, Mechanical 198, Roads 305 , and the Headquarters 263. Target population will be composed of all the 1072 employees in the Ministry of Road's payroll by July 2011.

\section{Sampling Frame}

Cooper \& Schindler (2011) and Mugenda \& Mugenda (1998) define sampling frame as the list of elements from which the sample is actually drawn. It's a published list or set in for identifying a population (Gall, Gall \& Borg, 2007). Employees register for all the departments employees were obtained from the payroll department through the Integrated Personnel Payroll Data (IPPD).

\section{Sampling Design}

Sampling involves any procedure that draws conclusion based on measurement of a portion of the population (Kothari, 2004). When the population is heterogeneous, Sekaran (1992) and Kothari (2004) recommends stratified random sampling since the method increases sample statistical efficiencies, provides adequate data for analyzing the various sub populations and enables different methods to be used depending on the characteristic of the stratum. The sample was developed using proportionate sampling strategy where the size of each stratum is proportionate to the population size of the stratum for better precision.

\section{Sample Size}

Sekaran (1992) argue that the size of a sample is a function of the variation in the population. This is guided by principles such as; dispersion, desired precision, error range and number of subgroups. Sampling Proportionate to size method will be used to come up with the sample. In this case the chosen proportion is $10 \%$ of each stratum. This is because of cost and time and also it is in line with Cooper and Schindler (2006), who suggested a range of $10 \%-30 \%$ to be representative. A sample of 108 was therefore be used.

\section{Data Collection Instruments}

This study required the collection of both primary and secondary data, and utilized both qualitative and quantitative data. Primary data collection instrument were the survey questionnaire. Secondary data was collected from Government publications, previous research work and journals.

\section{Data Collection Procedure}

The survey questionnaire were self administered to the respondents through the drop and pick method through the five divisions.

\section{Pilot Testing}

Pilot study was carried out to assess the feasibility, appropriateness and practicability of the research design as recommended by (Kothari, 2008 \& Zikmund et al, 2010). Data was analyzed using SPSS Version 17.0. ANOVA, correlations and regression analysis were used to check on relationship between the variables under the study.

\section{Descriptive Analysis \\ (i) Role of Performance Contracting}

\section{Results}

This section was investigating whether performance contracting generally has played a significant role in the service delivery. Findings presented in Table 2 indicate that twenty-four percent $(24 \%)$ of the respondents strongly agreed, thirty-three percent (33\%) agreed, twelve percent (12\%) disagreed, six percent (6\%) strongly disagreed while twenty-five percent $(25 \%)$ remained neutral. This implies that majority of the respondents (57\%) agreed that performance contracting had played a significant role in influencing employees' behavior in the department toward performance.

These findings are in consonance with the major studies done performance contracting in Kenya such as (Gakera et al 2013; GoK 2010; Akaraga 2008 and Kobia \& Mohammed 2006) whose studies concentrated on the impact of performance contracting since implementation in 2005. Further, Robins \&Judge (2013) argue that performance contracting has played a role in influencing employees' behavior towards expected or pattern. This is a pointer to the fact that performance contracting had played a role in improving enhancing performance in the civil service.

(ii) Global trend and ICT 
Information and Communication Technology (ICT) has had a lot of influence on every aspect of work in the modern organizations (McNabb,E, 2007) including government services. This question was investigating the effects of ICT role on performance contracting in enhancing effectiveness of performance.

Findings presented in Table 2 indicate that thirty-two percent (32\%) of the respondents strongly agreed, fortynine percent $(49 \%)$ agreed, three percent $(3 \%)$ disagreed while none strongly disagreed that ICT affect performance contracting. This implies that majority of the respondents $(81 \%)$ agreed that ICT had a positive influence in performance in the department.

These findings correlate with Luthans (2002) theory which argued that ICT has a sweeping effect in all organization functions. The theory noted that organizations are being melted and are dissolving into the ICT tool of communication. Robbins \& Judge (2009) noted that about 70\% of communication in today's organization is in electronic media. These findings points out to the fact that ICT is a major player in the success of the implementation of change in the civil service.

(iii)Employees Training on Performance Management

Performance contracting tool operates in a management style that involves breaking down work into activities, setting targets based on the activities, measurement and evaluation the targets and using the generated information to guide future activities (World Bank, 1995:171). This part was investigating whether employees had been trained on this form of performance management.

Findings presented in Table 2 indicate that fifteen percent (15\%) of the respondents strongly, twenty-four percent $(24 \%)$ agreed, twenty-eight percent $(28 \%)$ were neutral, twenty-two percent disagreed while eleven percent $(11 \%)$ strongly disagreed. This implies that a slight majority $(39 \%)$ of the respondents agreed as compared to thirty-three percent $(33 \%)$ of respondents who disagreed having received any training on performance management.

These findings correspond and lime to findings by Kobia \& Mohammed (2006) who observed that training had been carried out to the majority (72\%) of the public servants. Findings also correlate to the government policy on training GoK (2005) that required all employees to have a minimum of five (5) training days per year. These results imply that employees do not understand the paradigm of performance and its management yet they are required to be managed and perform through the same.

(iv) What Gets Measured Gets Done

This section was investigating the respondents' take on "What get measured gets done". Findings presented in Table 2 indicate that sixteen percent $(16 \%)$ of the respondents strongly agreed, twenty-five percent $(25 \%)$ agreed, thirty-eight percent (38\%) disagreed; seven percent (7\%) strongly disagreed while fourteen percent $(14 \%)$ remained neutral. This implies that majority of the respondents $(59 \%)$ disagreed that measuring employees' output influence overall performance.

These findings disagree with a theory by Drucker (1998) that argued that unless employees work is measured, production expected is to the minimum because anything is acceptable. Measurement provides a basis for communication. This also contradicts Tayloism or scientific management theory that is based on measurement and standards. These findings points out to the fact that measurement has not been taken very positively in the civil service probably because it exposes the employees' laxity.

\section{(v) Ranking Enhances Performance}

Ministries, Departments and Agencies are ranked annually to display the position for each performance in comparison to the others. Respondents were required to comment on the effects of ranking on the performance. Findings presented in Table 2 indicate that sixteen percent $(16 \%)$ of the respondents strongly, twenty-two percent $(22 \%)$ agreed, twenty-eight percent $(28 \%)$ disagreed while nine percent $(9 \%)$ strongly disagreed.

This implies that employees for (38\%) or against (37\%) tallied which contradicts the spirit behind measurements according to GoK (2005) because ministries were expected to share their strength to minimize on the weakness. Studies by (Korir, 2010; Akaranga, 2010; Muthaura, 2007; and Kobia \& Mohammed, 2006) observed that performance contracting has become key to the achievements of results in the public sector following a move by the government to open up its public coffers for scrutiny and accountability. 
Table 2 Role of Performance Contracting

\begin{tabular}{llllll}
\hline Performance Contracting & $\begin{array}{l}\text { Strongly } \\
\text { Disagree\% }\end{array}$ & $\begin{array}{l}\text { Disagre } \\
\mathbf{e} \%\end{array}$ & $\begin{array}{l}\text { Neither } \\
\text { \% }\end{array}$ & $\begin{array}{l}\text { Agree } \\
\text { \% }\end{array}$ & $\begin{array}{l}\text { Strongly } \\
\text { Agree \% }\end{array}$ \\
\hline $\begin{array}{l}\text { Role } \\
\text { Global trend and ICT }\end{array}$ & 6 & 12 & 25 & 33 & 24 \\
$\begin{array}{l}\text { Employes training on performance } \\
\text { management }\end{array}$ & 15 & 3 & 16 & 49 & 32 \\
What gets measured gets done & 7 & 24 & 28 & 22 & 11 \\
Ranking enhances performance & 9 & 38 & 14 & 25 & 16 \\
\end{tabular}

\section{Inferential Analysis}

(i) Factor Analysis

Findings presented in Table 3 presents the components and the decision made for the performance contracting, the independent variable on the effectiveness of performance. The variable was represented through eleven (11) factors. Nine factors were retained for subsequent analysis since they all met the threshold value of 0.5 (David et al 2010). Two factors did not meet the threshold value and were dropped.

Table 3 Factor Analysis for Performance Contracting

Component Matrix

\begin{tabular}{lll}
\hline Performance Contracting & Component & Decision \\
\hline Performance Contracting Role & .941 & Retain \\
Global trend and ICT & .941 & Retain \\
Employees training on performance management & .907 & Retain \\
Ranking enhances performance & .566 & Retain \\
What gets measured gets done & .543 & Retain \\
\hline
\end{tabular}

(iii) Reliability Test for Performance Contracting

Findings presented in Table 4 below shows the Cronbach Alpha Coefficient for organizational effectiveness of 0.845. The coefficient was generated after dropping the two factors that failed to satisfy the factor analysis computed threshold value of 0.4. This is acceptable because it is above the Cronbach Alpha Coefficient of 0.7 and therefore qualifies for subsequent analysis.

Table 4 Reliability Test for performance Contracting

\begin{tabular}{lcc}
\hline Reliability Statistics & & \\
\hline & Cronbach's Alpha & N of Items \\
& 0.845 & 9 \\
\hline
\end{tabular}

Correlation between Performance Contracting and Performance Effectiveness

This section was investigating the correlation between performance contracting and performance effectiveness. Table 5 presents the findings and indicates that performance contracting has a strong and positive Pearson Correlation coefficient of 0.596 at a p-value of 0.000 . This implies that performance contracting is significant and has positive influence on performance effectiveness in the civil service since the $p$-value $(p=0.000)$ is well within the threshold value of $(0.05),(p<0.05)$.

Table 5 Correlation between Performance Contracting \& Performance Effectiveness Correlations

\begin{tabular}{llll}
\hline & & Performance & Performance Contracting \\
\hline Performance Effectiveness & Pearson Correlation & 1 & $0.596^{* *}$ \\
& Sig. (2-tailed) & & 0.000 \\
Performance Contracting & $\mathrm{N}$ & 102 & 102 \\
& Pearson Correlation & $0.596^{* *}$ & 1 \\
& Sig. (2-tailed) & 0.000 & 102 \\
\hline
\end{tabular}

**. Correlation is significant at the 0.01 level (2-tailed).

\section{Regression Fitting of Performance Contracting on Performance Effectiveness}

This section was analyzing diagrammatically the relationship between performance contracting and performance effectiveness. Figure 6 presents a scatter plot with a fitted regression line. The figure indicates that the observed 
plots and ideal line between performance contracting and effectiveness of performance are positively related. This implies that performance contracting affects performance effectiveness positively and in a linear way.

Table 6 presents the R-square value which is the amount an independent variable is able to explain on the dependent variable. The value for R-squared $(0.316)$ in the table implies that performance contracting explains $31.6 \%$ of the effectiveness of performance.

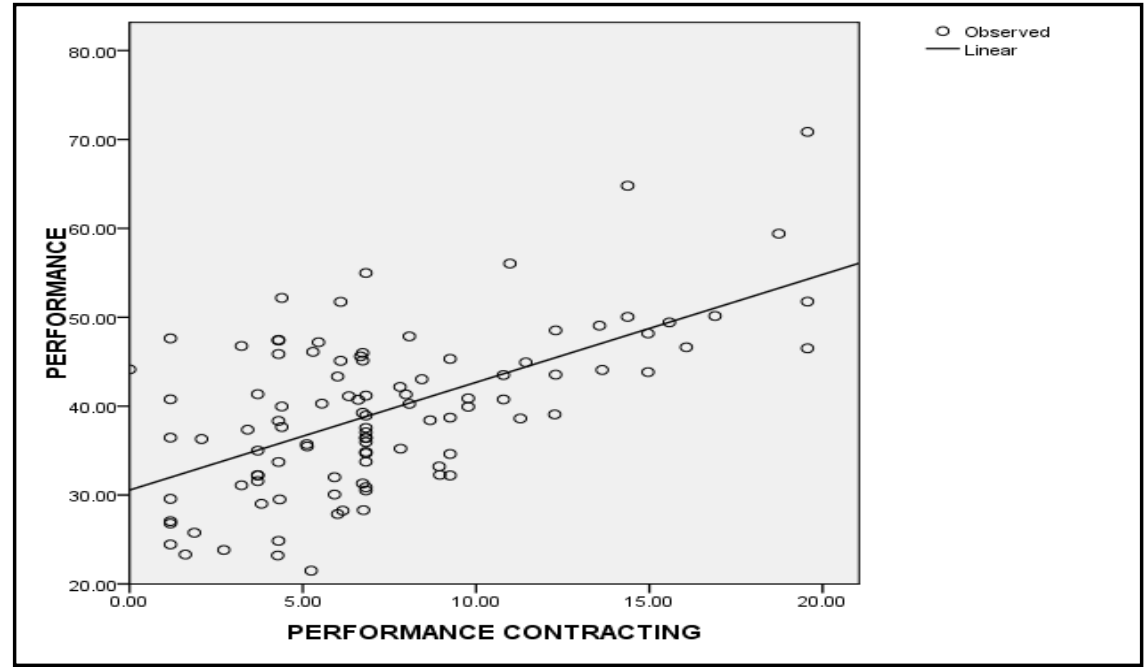

Figure 2 Scatter Plot of PC on Performance effectiveness with a Fitted Regression Line

Table 6: R-Square Value for Performance Contracting on Effectiveness of Performance

\begin{tabular}{ccc}
\hline Model & $\mathrm{R}$ & R Square \\
\hline 1 & 0.562 & 0.316 \\
\hline
\end{tabular}

Analysis of Variance (Anova)

A one-way analysis of variance (Anova) tests allow determination whether one given factor or variable (performance Contracting) has a significant effect on other variables under study. A significant p-value resulting from a one-way Anova test would indicate that a variable is differentially expressed in at least one of the variables analyzed. P-value indicates the probability of getting a mean difference between the groups as high as what is observed by chance.

Table 7 present the results for the Anova test. All the independent variables were weighted as the performance effectiveness against performance contracting. Findings indicate that performance contracting is significant and enhances performance effectiveness as it give an F-value of 46.098 at a p-value of 0.000 . This is significant since it's less the threshold p- value of 0.05 .

Table 7 Analysis of Variance Table: PC and Performance Effectiveness

\begin{tabular}{lllllll} 
Anova & \multicolumn{1}{l}{ ( } & Sum of Squares & Df & Mean Square & F & Sig. \\
\hline 1 & Regression & 6662.781 & 1 & 6662.781 & 46.098 & $.000^{\text {a }}$ \\
& Residual & 14453.490 & 100 & 144.535 & & \\
& Total & 21116.271 & 101 & & &
\end{tabular}

a. Predictors: (Constant), Performance Contracting

b. Dependent Variable: Performance Effectiveness

c. Weighted Least Squares Regression - Weighted by Job Title

\section{Regression Model between PC and Performance Effectiveness}

This is a mathematical equation that relates performance contracting and effectiveness of performance. Table 8 presents the values of the generated model and indicate that without performance contracting, performance effectiveness stand at 30.793 units. With introduction of performance contracting, a unit increase in performance contracting result to increasing performance effectiveness by 1.22 units. This is significant because the value is within the acceptable $\mathrm{p}$-value of $0.000(\mathrm{p}<0.05)$. The model can be presented by the model;

Performance Effectiveness $=30.793+1.22 *$ Performance contracting.

These findings agree with most of the studies on performance contracting by the government and other scholars who noted that that performance contracting improved effectiveness of performance (GoK 2010; Prajapati 2009; 
Akaranga 2008; Kobia \& Mohammed 2006) though these studies were highly descriptive and qualitative and not quantitative. Performance contracting was premised that it would improve performance effectiveness in the civil service (GoK, 2003) and the findings quantify its magnitude, effect and agrees with past studies.

Table 8 Regression Model Matrix; PC and Performance Effectiveness

Coefficients

\begin{tabular}{|c|c|c|c|c|c|c|}
\hline \multirow[b]{2}{*}{ Model } & & \multicolumn{2}{|c|}{ Unstandardized Coefficients } & \multicolumn{2}{|c|}{$\begin{array}{l}\text { Standardized } \\
\text { Coefficients }\end{array}$} & \multirow[b]{2}{*}{ Sig. } \\
\hline & & B & Std. Error & Beta & $\mathrm{T}$ & \\
\hline \multirow[t]{2}{*}{1} & (Constant) & 30.793 & 1.506 & & 20.444 & .000 \\
\hline & Performance Contracting & 1.220 & .180 & .562 & 6.790 & .000 \\
\hline
\end{tabular}

A. Dependent Variable: Performance Effectiveness

b. Weighted Least Squares Regression - Weighted by Job Title

\section{Summary, Conclusion And Recommendations}

Summary; Performance Contracting on Performance Effectiveness

The objective of this study was to establish the effects of performance contracting on performance effectiveness in the civil service. Various methods were used to arrive at the findings which included descriptive and inferential statistics. Correlations, ANOVAs and regression analysis were used.

Findings indicate that performance contracting leads to improvement in performance effectiveness in the civil service. This observation was arrived at since the various factors measured that led to performance effectiveness proved worth. Such factors included organizational productivity, employees' motivation, organizational effectiveness and organizational culture. Government goodwill which is interpreted as a policy was also measured.

\section{Conclusion; Contribution of Performance Contracting on Organization Productivity}

The study concludes that performance contracting tool leads to improvement in performance effectiveness in the civil service. Since implementation of performance contracting in the civil service in Kenya, performance effectiveness has increased significantly. It can be concluded from the results presented in this study that there exists a positive and significant relationship between performance contracting and performance effectiveness and that it's a path worth investing in.

\section{Recommendation for Improvement in Productivity in the Civil Service}

Overall, it is recommended that various measures need to be put in place to entrench performance contracting in entire public service and if possible to the smallest units of operation. Measured factors leading to effectiveness of performance such as organizational productivity, employees' motivation, organizational effectiveness and organizational culture and government policy need to be broken down to their specific indicators to enable close follow up. Employees' motivation, involvement and training on performance contracting play a key role hence need for strengthening.

Further research to reveal the role of performance contracting on the above variables is highly recommended.

[1]. Akaranga, E. M. (2008). The Process and Effects of Performance Contracting in Kenyan Public Sector, MBA Project; United States International University (USIU), Nairobi.

[2]. Armstrong and Baron, (2002). Strategic Human Resource Management: The Key to Improved Business performance, Kogan Page 45, London

[3]. Bouckaert, F.G., Verhoest, K., \&De Cortek, (1999). Public Sector Performance Contracting in Belgium, Retrieved July 2011 Website: http://www.unea.org

[4]. Cole G.A. (1997). Management Theory and Practice, $6^{\text {th }}$ Edition.

[5]. Cole G.A. (2004). Organization Behaviour, TJ International, Padstow Cornwall, UK

[6]. Cooper, D. R. and Emory C W, (1995). Business Research Methods, Psychological Bulletin, 108, pp. 171-194

[7]. Cooper, D. R. and Schindler, S. P. (2006). Business Research Methods $9^{\text {th }}$ Edition McGraw-Hill Publishing Co. Ltd., New Delhi

[8]. Cooper, D. R. and Roger (2011). Business Research Methods $11^{\text {th }}$ Edition McGraw- Hill Publishing Co.LTD, New Delhi

[9]. Cronbach, L J. (1990). Essential of Tests Psychological Testing $\left(5^{\text {th }}\right.$ Ed. New York: Harper and Row.

[10]. Croncbach, L. J. (1951). Coefficient Alpha and Internal structure of Tests Psychometrika, 16, 297-334

[11]. DPM (2004). Targeted Voluntary Early Retirement Scheme 2004-2008

[12]. Drucker, P. Drucker, (1998). The effective Executive, Heinemann

[13]. Gakere

[14]. GOK, (2001). A Strategy for Performance Improvement in the Public Service. Nairobi: Government Printer

[15]. GOK, (2003). Economic Recovery Strategy for Wealth and Employment Creation. Nairobi: Government Printer.

[16]. GOK, (2005). Recruitment and Training Guide Nairobi: Government Printer

[17]. Grapiret, G. (1990). Public Sector Performance Contracting in France, France

[18]. Kobia, M. \& Mohammed, N (2006). The Kenyan Experience with Performance Contracting Government Printer: Nairobi 
[19]. Kothari, C.R. (2004). Research Methodology: methods and Techniques $2^{\text {nd }}$ Ed. New Delhi, Washua Prakasha Publishers

[20]. Kothari, C.R. (2008). Research Methodology: methods and Techniques $2^{\text {nd }}$ Ed. New Delhi, Washua Prakasha Publishers

[21]. May, P. (2005). Best Practice and Trends in Performance Based Contracting, Retrieved July 2011, Website: www.unea.org

[22]. Mbithi, P. (1996). Strategic Planning in the Public Service; Speech delivered during Senior Government officers at Mombasa

[23]. Morgan, P. (2000). Paradigms Lost and Paradigms Regained? Recent Developments and New Directions for HRM/OB in the UK and USA', International Journal of HRM, 11:4, August 2000, pp. 853-866

[24]. Mugenda, A. G. (2008). Social Science Research, Kijabe Printing Press, Kenya

[25]. Mugenda, O. M. \& Mugenda, A. G. (1999). Research methods: Quantitative \& Qualitative Approaches. Nairobi, Kenya: ACTS press

[26]. Muthaura, F. (2007). Performance Contracting in Kenya; Restoring Faith in government through Innovation to promote Quality of Public Service

[27]. Metawie, M. \&Gilman, M (2006). Problems with the Implementation of Performance Measurement System in United Kingdom. UK

[28]. Ndung'u, M. N. (2009). Performance Management and Contracting, Kenyan Perspective, Jitegemea Press, Nairobi Kenya

[29]. Ntoiti, J (2013) Determinants of Financial Distress facing Local Authorities in Service Delivery in Kenya, Unpublished, JKUAT

[30]. Obong'o Odhiambo, (2009). Historical Perspective of the Performance Contracting in Kenya

[31]. Paul \& Anatharaman (2003). Impact of People Management Practices on organizational Performance: Analysis of a Causal Model', International Journal of HRM, 14:7, pp. 1246-1266

[32]. Prajapati, T (2009) Performance Contracting in Kenya

[33]. RBM Guide, Kenya (2005). Results Based Management: Training Manual. Kenya 9 (3)

[34]. Republic of Kenya, (2005). Economic Survey, Nairobi, Government Printers

[35]. Republic of Kenya, (2005). Sensitization/Training Manual on Performance Contracts in the Public Service, Performance Contracts Steering Committee

[36]. Shaver, M. (2006). Using Laverage to Drive Results. Performance Contracting in Illinois, USA

[37]. Sekaran, U. (2003). Research Methods for Business: A Skill Building Approach, $4^{\text {th }}$ Edition, Inc \& Sons New York

[38]. Sekaran, U. \& Roger, B. (2009). Research Methods for Business, A Skill Building Approach, John Willey \& Sons Ltd

[39]. Taylor,F.W. (1947). Scientific Management, Harpar and Row

[40]. Zikmund, W.G.; Babin, B.J.; Carr, J.C.; Griffin, M. (2010). Business Research Methods $8^{\text {th }}$ Edition, McMillan Publishers 